\title{
Pemanfaatan Teknologi Sistem Informasi untuk Meningkatkan Penjualan Hasil Produk UMKM Logam di Kota Pasuruan
}

\author{
Mochamad Mas'ud \\ Mechanical Engineering University Yudharta Pasuruan \\ masud.teknik@yudharta.ac.id
}

\begin{abstract}
The Metal Crafters in Pasuruan City who are members of the Indonesian Prosperous (PASINDO) oversees about 300 UMKM of metal. Partners taken by machining and casting groups and packing groups. Metal Craftsman Company manages the management manually, if there is ordering according to job order recorded in big book and finance is not set. Factors in focusing assistance to metal craftsmen under the auspices of Pasindo is knowledge of management information technology and marketing to increase sales. Output targets implemented include conducting financial management and marketing training, operationalizing application systems, entry training and data updating in databases, as well as providing order management training through e-commerce application systems. Method offered approach Metal business unit as seller and buyer based on information technology include: Observation on business partners, designing and making ecommerce application system, and training to Partners. Retail data for 14 months before using a Web-based sales application on a sample of 30 products generated a net profit of R. 5,120,000. Sales for 2 months after using the Web application generated a net profit of Rp. 4,356,000. It experienced an increase in profit of Rp. 1,812,286 every month after using a Web-based sales app (E-Commerce).
\end{abstract}

Keywords: Metal Crafters, Training and E-commerce

\section{Pendahuluan}

Dalam era globalisasi kemampuan produksi dan pemasaran dilandaskan pada kemampuan menciptakan produk yang dapat dijual dan mampu bersaing secara global dengan memanfaatkan perkembangan teknologi. Kemampuan bersaing dan meningkatkan kinerja diperlukan dalam situasi persaingan global yang makin tajam dan kehendak untuk mengantisipasi ketertinggalan. Dengan demikian pengembangan industri, khususnya UMKM logam kota Pasuruan perlu tetap memanfaatkan keunggulan komparatif yang dimiliki, namun harus bergerak menuju penciptaan keunggulan kompetitif yang dinamis. Bisnis yang dilakukan melalui internet menggunakan sistem e-commerce akan membantu penjualan. Ecommerce merupakan satu set dinamis teknologi, aplikasi, dan proses bisnis yang menghubungkan 
perusahaan, konsumen, dan komunitas tertentu melalui transaksi elektronik dan perdagangan barang, pelayanan, dan informasi yang dilakukan secara elektronik. ${ }^{1}$

Peranan sistem informasi dalam suatu organisasi tidak diragukan lagi. Dukungannya dapat membuat sebuah perusahaan memiliki keunggulan kompetitif, yang berarti bahwa suatu perusahaan dapat bersaing dengan perusahaan lain dengan mempergunakan sistem informasi. Keberadaan sistem informasi tidak hanya bermanfaat bagi perusahaan, tetapi juga bagi konsumen. Berkat sistem informasi konsumen dengan mudah dapat memperoleh informasi produk, dan bahkan melakukan pemesanan barang melalui internet ${ }^{2}$.

Sebagai contoh pada toko Omah Mode Kudus merupakan suatu toko di kota Kudus yang bergerak di bidang fashion seperti : baju, celana, topi, jaket, kaos, sweater dan lainnya. Namun sistemnya banyak masalah khususnya di luar kota Kudus. Pihak Vendor belum memiliki media khusus untuk mempromosikan produknya. Konsumen langsung datang ke toko apabila ingin mendapatkan informasi dan memesan produk, serta konsumen lewat sms/telepon jika mengetahui stok koleksi tertentu. Berdasarkan masalah tersebut diperlukan aplikasi e-commerce. ${ }^{3}$

Dengan pemanfatan teknologi internet diharapkan dapat membantu memberikan manfaat yang besar terhadap dunia bisnis yang kompetitif. Perusahaan tersebut yang mampu melakukan implementasi teknologi dalam meningkatkan persaingan bisnis dan penjualan produk dengan menggunakan electronic commerce (e-commerce) untuk memasarkan berbagai macam produk atau jasa. ${ }^{4}$

Keuntungan dari penerapan E-Commmerce dari segi pelanggan dapat memberikan informasi dan masukan yang dapat membantu mendorong penjualan, kenyamanan dan berbagai produk yang diinginkan dan barang yang akan dipesan akan dikirim. Dari segi perusahaan sebagai penghibur dan menyediakan fasilitas bagi pelanggan untuk menjual barang yang tidak diinginkan serta membangun ikatan yang kuat dengan pelanggan. Segi keuangan lebih meningkat penjualannya. ${ }^{5}$

Persaingan yang semakin ketat dalam dunia bisnis dan usaha mendorong setiap perusahaan untuk lebih kreatif dan mampu mengelolah bisnis. Perusahaan dapat meningkatkan kemampuannya dengan

1 Onno W. Purbo., Buku Pintar Internet Membangun Web E-Commerce (Yogyakarta: Diglib AMIKOM, 1996).

2 Muh Barid Nizarudin Wajdi, "Paradigma Perges eran Educational Technology Menuju Instructional Technology" (2017).

3 Sri Haryanti and Tri Irianto, "Rancang Bangun Sistem Informasi E-Commerce Untuk Usaha Fashion Studi Kasus Omah Mode Kudus," Journal Speed 3, no. 1 (2011): 8-14.

${ }^{4}$ Dewi Irmawati, "Pemanfaatan E-Commerce Dalam Dunia Bisnis," Jurnal Ilmiah Orasi Bisnis 6, no. 2 (2011): 95-112.

5 I Gusti Made Karmawan, "DAMPAK PENINGKATAN KEPUASAN PELANGGAN DALAM PROSES BISNIS E-COMMERCE PADA PERUSAHAAN AMAZON. COM,” ComTech 5, no. 2 (2014): 748-762.

Volume 1, Number 2, November 2017 | 186 Penguatan Pengelolaan Ternak Wakaf Hibah Produktif melalui Fermentasi Pakan Ternak sebagai Alternatif Pemberdayaan Santri menuju Pesantren Yatim yang Mandiri 
mengembangkan system informasi sesuai dengan kemajuan teknologi yang dimiliki ${ }^{6}$. Sistem informasi merupakan seperangkat alat, data dan prosedur yang bekerja secara bersama-sama untuk memberikan hasil berupa informasi, maka perlu metode dalam merancang Web.

Dalam hal ini contoh Perancangan Web kelas online menggunakan metode WISDM (Web Information System Development Methodologi) dengan pemodelan menggunakan pendekatan UML (Unifled Modeling Languange) dapat memberikan sebuah kepuasan pelanggan. ${ }^{7}$ Metode penelitian exploratory dengan teknik analisis data menggunakan Struktural Equation Modeling (SEM), component based Partial Least Squers (PLS). Jumlah resonden sebanyak 60 mahasiswa aktif yang pernah bertransaksi secara online melalui $e$ commerce, dengan teknik perceived usefulness, perceived of use berpengaruh signifikan terhadap attitude mahasiswa STMIK dalam online shopping, serta berpengaruh signifikan terhadap intention to use. 8

Menurut Nugrahani Shanti, E-commerce merupakan salah satu cara yang dapat dilakukan oleh pelaku usaha kecil dan menengah (UKM) untuk memasarkan produknya selain dapat memperluas akses pasar. UKM dapat langsung berkomunikasi dengan pembelinya, sehingga mereka dapat memperoleh keuntungan yang lebih besar. ${ }^{9}$

Permasalahan UKM dalam memperluas akses pasar dan menembus pasar ekspor bisa diatasi dengan menggunakan e-commerce. Tetapi kendalanya penguasaan teknologi para pengusaha yang masih rendah dan adanya keengganan untuk mengoptimalkan pengguna e-commerce dalam bisnis mereka. ${ }^{10}$

E-Commerce dengan pengimplementastan CRM di dalamnya dapat menjadi jalan keluar untuk Dolanan Puzzle dalam mengembangkan usahanya. Adanya E-Commerce sebagai toko online Dolanan Puzzle memudahkan pelanggan dalam mencarinya. Promosi dari Dolanan Puzzle pun dapat ditingkatkan dengan penerapan CRM pada E-Commerce Dolanan Puzzle tersebut. ${ }^{11}$

6 M Ikhsan Setiawan and agus sukoco, "2015 PENGEMBANGAN PUSAT BISNIS (CENTRAL BUSINESS DISTRICT) DENGAN POLA KERJASAMA PEMERINTAH-SWASTA (KASUS WILAYAH KAKI SURAMADU SISI SURABAYA)," doi.org (2017), accessed October 21, 2017, https://osf.io/preprints/inarxiv/kbwme/.

7 Sandy Mawardi, Eri Satria, and Dewi Trisnawati, "Peran cangan Web Kelas Online Dengan Metodelogi WISDM Berbasis Learning Manajement System Di MAN PAMEUNG PEUK," Jurnal Algoritma 9, no. 37 (2012): 17.

${ }^{8}$ Iwan Sidharta and Rahmahwati Sidh, "Pengukuran Persepsi Manfaat Dan Persepsi Kemudahan Terhadap Sikap Serta Dampaknya Atas Penggunaan Ulang Online Shopphing Pada E-Commerce,” Jurnal Computech \& Bisnis 8, no. 2 (2014): 92-100.

9 Dewi Shanti Nugrahani, "E-Commerce Untuk Pemasaran Produk Usaha Kecil Dan Menengah," Segmen: Jurnal Manajemen dan Bisnis 7, no. 1 (2011): 1-16.

10 Nuryanti, "Peran E-Commerce Untuk Meningkatkan Daya Saing Usaha Kedi Dan Menengah UKM)," Jurnal Ekonomi 21, no. 4 (2013): 1-15.

${ }^{11}$ Handaru Eri Pramudiya, Yonathan Dri Handarkho, and Flourensia Sapty Rahayu, "Pengimplementasian CRM Pada Pembangunan E-Commerce Untuk Usaha Mikro Kecil Menengah ( Studi Kasus : Dolanan Puzzle )," Buana Informatika 6, no. 4 (2015): 257-268. 
UMKM logam kota Pasuruan yang tersebar di Kelurahan Mayangan, Kelurahan Ngemplakrejo dan disebagian wilayah Kecamatan Gadingrejo Kota Pasuruan ini menghasilkan berbagai macam produk industri logam yang beragam, diantaranya :

- Komponen diesel alat-alat pertanian (Nepel, Pully dan lain-lain)

- Aksesoris sepeda motor (Tutup Pentil, Spion, Pengaman Knalpot,Tutup Oli, Handle, Jalu hand part, Planger, Ring plat nomer, dil)

- Aksesoris Mobil (Planger, Stank Spion dan Wiper)

- Spare part mobil dan motor (As roda, Bosch slip, baut manipol dan manipol, filter)

- Peralatan rumah tangga (Asbak, aksesoris interior lampu, aksesoris lafal)

- Aksesoris Meubel (handle, engsel dan aksesoris lainnya)

Hingga tahun 2014 jumlah perajin industri logam yang terdapat di Kota Pasuruan sebanyak \pm 400 perajin logam.12 Pekerja dengan kompetensi keahlian perajin logam (skill) pada UMKM logam cukup potensial untuk dapat dikembangkan. Namun demikian bukanlah berarti UMKM logam tidak mempunyai masalah didalam tubuhnya. Sehingga pola pengembangan UMKM logam harus dilakukan lebih terarah dan terkoordinasi agar hasil yang dicapai lebih efektif melalui suatu mekanisme pengembangan yang terencana. Selanjutnya masalah-masalah yang dihadapi oleh UMKM logam dilakukan suatu analisa dan identifikasi masalah yang lebih spesifik yaitu dengan cara brainstorming dan peta kognitif. Masalah yang aktual direkomendasikan adalah masalah teknologi sebesar 65,5\%, kemudian faktor pemasaran sebesar $10 \%$ dan diikuti faktor manajemen sebesar 24,5\%, maka dapat ditentukan program yang digunakan dalam pengembangan UMKM logam yaitu faktor pemasaran dan manajemen. Kondisi UMKM perajin logam di Kota Pasuruan rata-rata hanya sebagai Job order.

Manfaat teknologi informasi bagi unit usaha pengrajin adalah untuk menghemat waktu, memperbaiki mutu, mengurangi tenaga kerja, meningkatkan efektifitas biaya, berbagi informasi, memperbaiki ketrampilan pekerja, memperbaiki komunikasi di dalam maupun dengan dunia luar dan menfasilitasi akses terhadap informasi perdagangan ${ }^{13}$.

12 “Industri Pasuruan,” Http:/ / pasuruankota.go.id.

13 Muh. Barid Nizaruddin Wajdi, Yuli Choirul Ummah, and Devit Etika Sari, "UKM Development Business Loan," IJEBD (International Journal Of Entrepreneurship And Business Development) 1, no. 1 (October 1, 2017): 99-109, accessed November 9, 2017, http://jurnal.narotama.ac.id/index.php/ijebd/article/view/350.

Volume 1, Number 2, November 2017 | 188 Penguatan Pengelolaan Ternak Wakaf Hibah Produktif melalui Fermentasi Pakan Ternak sebagai Alternatif Pemberdayaan Santri menuju Pesantren Yatim yang Mandiri 
Pemberdayaan melalui penyuluhan dengan dilengkapinya akses internet, hal ini akan memudahkan unit usaha masyarakat dan UMKM memperoleh informasi berupa inovasi teknologi dan kelembagan yang dibutuhkannya dalam mengupayakan kesejahteraan masyarakat yang menjadi tugas pokok, fungsinya serta tanggung jaw abnya. Masalah internal yang dihadapi UMKM pengrajin logam Kota Pasuruan yaitu: rendahnya kualitas SDM dalam manajemen, organisasi, penguasaan teknologi, dan pemasaran.

Pendampingan diharapakan bertujuan: (1) Membentuk/mengembangkan sekelompok masyarakat yang mandiri secara ekonomis, (2) Meningkatkan pengetahuan teknologi informasi, (3) Meningkatkan pengetahuan dan kemampuan manajerial produksi, (4) Meningkatkan pendapatan unit usaha perajin. Target luaran yang akan dihasilkan dalam program IbM yaitu memberikan pelatihan kepada mitra yang meliputi: (1) pelatihan manajemen keuangan dan pemasaran, (2) Operasional sistem aplikasi, (3) Pelatihan entri dan update data di database sistem aplikasi e-commerce, (4) serta Memberikan pelatihan manajemen order/pemesanan melalui sistem aplikasi e-commerce.

Pada Penelitian Sebelumnya Pemanfaatan Teknologi internet oleh UKM yang memakai internet menunjukkan bahwa pelaku bisnis sudah mempunyai pandangan yang strategis dalam upaya memanfaatkan teknologi internet, seperti menjaga hubungan dengan pelanggan, menginformasikan usaha/bisnis kepada pihak lain dan mencari informasi. Kendalanya di minimnya sumber daya manusia pada UKM yang dapat mengoperasikan komputer dan internet. ${ }^{14}$

Pengembangan sistem e-commerce UKM dilakukan dengan menggunakan metode daur hidup pengembangan perangkat lunak (software development life cycle) yang terdiri dari analisis dan definisi kebutuhan system, desain system dan perangkat lunak, implementasi dan pengujian unit, integrasi dan pengujian system, dan pengoperasian dan pemeliharaan. Sistem berbasis open source software dengan menggunakan bahasa pemprograman PHP versi 5.4.3 dan html, basis data My SQL dan sever Apache.15

\section{Metode}

Strategi yang dilakukan untuk mencapai kondisi yang diharapkan untuk meningkatkan penjualan hasil produk UMKM pengrajin logam adalah PAR (Participatory Action Research) alat yang bersifat partisipasi berupa Technology of Participation (ToP) berbasis teknologi informasi.

14 Wheny Kh ristianto, "Penggunaan Teknologi Informasi Di Usaha Kecil Men engah (Studi Pada Usaha Kecil Menengah Di Wilayah Gedong Meneng)" (Universitas Islam Lamongan, 2012).

15 Ridwan Suhud and M. Yudhi Rezaldi, "E-Commerce System Development of Society of Small and Medium Enterprises Karya Mandiri in Tegal," Widyariset 17, no. 1 (2014): 49-58.

Volume 1, Number 2, November 2017 | 189

Penguatan Pengelolaan Ternak. Wakaf Hibah Produktif melalui Fermentasi Pakan Ternak sebagai Alternatif Pemberdayaan Santri menuju Pesantren Yatim yang Mandiri 
1. Bekerjasama dengan PASINDO untuk mendiskusikan topik yang hendak diabdikan yaitu pemberdayaan usaha ekonomi produktif bagi masyarakat dan mencari data dalam pemecahan masalah.

2. Menyelenggarakan pelatihan, dengan materi: Pemanfaatan komputer dalam strategi promosi dan usaha, Manajmen usaha, manajemen sumber daya manusia, dan pemasaran, Peningkatan keterampilan, berupa pelatihan sistem aplikasi web E-Commerce.

Pihak yang terlibat Para Perajin Logam di Kota Pasuruan yang tergabung dalam Para Emerta Sejahtera Indonesia (PASINDO) membawahi kurang lebih 300 UMKM logam. Tempat pelatihan program ini di kantor PASINDO di Jl. Irian Jaya Gg Anggrek N0. 197 Kota Pasuruan. Di Program IPTEK bagi masyarakat kerjasama dengan PASINDO dalam pengambilan sampel perajin logam pada dua mitra untuk sebagai pelatihan yaitu kelompok Pemesinan dan Pengecoran serta kelompok Packing yaitu. CV Citra Prakarsa Kebangkitan (kelompok Packing), UD Karya Persada (kelompok Pemesinan dan Pengecoran), UD Teknik Persada (kelompok Pemesinan dan Pengecoran). Waktu pendampingan mulai bulan Mei - September 2017.

\section{Hasil dan Diskusi}

Guna memenuhi kebutuhan untuk meningkatkan promosi, pemasaran dan penjualan produkproduk di perajin logam baik kelompok pemesinan dan pengecoran di Kota Pasuruan, maka Solusi luaran dari IbM adalah untuk membuat sistem aplikasi web yang digunakan oleh pelaku usaha dan pembeli/buyer produk dalam melakukan jual beli. Pembeli juga dapat melihat produk-produk yang ditawarkan disetiap usaha dan dapat melakukan transaksi pembelian melalui sistem tersebut. Sistem aplikasi web ini dibangun berbasis e-commerce.

Tujuan menggunakan E-Commerce pada UMKM perajin logam Kota Pasuruan sebagai sistem transaksi adalah:

- Dapat meningkatkan market exposure (pangsa pasar).

- Menurunkan biaya operasional (operating cost).

- Melebarkan jangkauan (global reach).

- Meningkatkan supply management.

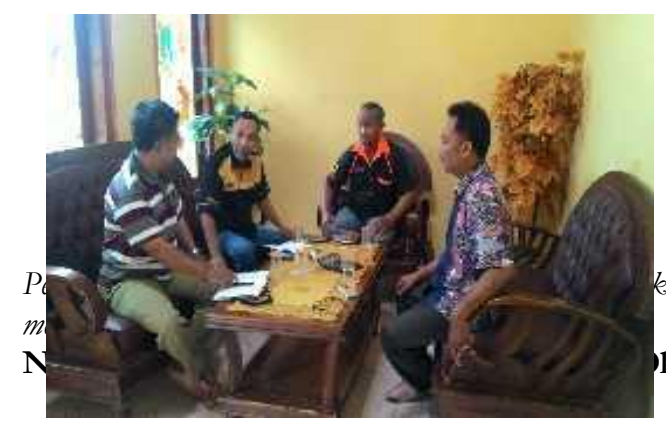

Untuk memenuhi target luaran maka perlu survey lokasi kelompok pengrajin logam dalam memetakan kondisi mitra dan diskusi untuk mencari pemecahan masalah. Kemudian di 
ENGAGEMENT

Gurnal Pengabdian Kepada Masyarakat

ISSN : 2579-8375 (Print)

ISSN : 2579-8391 (Online)
This work is licensed under a Creative Commons

Attribution-ShareAlike 4.0 International License. CC BY SA

diskusikan lagi pada pengurus PASINDO dalam membuat jadwal pelatihan.

Target luaran pada aspek manajemen yang akan dihasilkan dalam program IbM yaitu:

Gambar 1. Persiapan Kegiatan Pelatihan

1. Memberikan pelatihan kepada mitra yang meliputi pelatihan pemasaran.

2. Memberikan pelatihan operasional sistem aplikasi, pelatihan entri dan update data di database sistem aplikasi e-commerce

3. Memberikan pelatihan pengolahan dan manajemen order/pemesanan melalui sistem aplikasi e-commerce

Pada perancangan data base dan pembuatan coding sistem informasi diperlukan data pembukuan jual beli, spesifikasi produk dan harga untuk penggunaan data pembuatan data base pada sistem informasi e-commerce. Kemudian di uji coba dan di implimentasikan sistem informasi tersebut.

Menyelenggarakan pelatihan operasional sistem aplikasi, palatihan entri dan upload data dan pengolahan manajemen order menggunakan sistem aplikasi penjualan berbasis web.

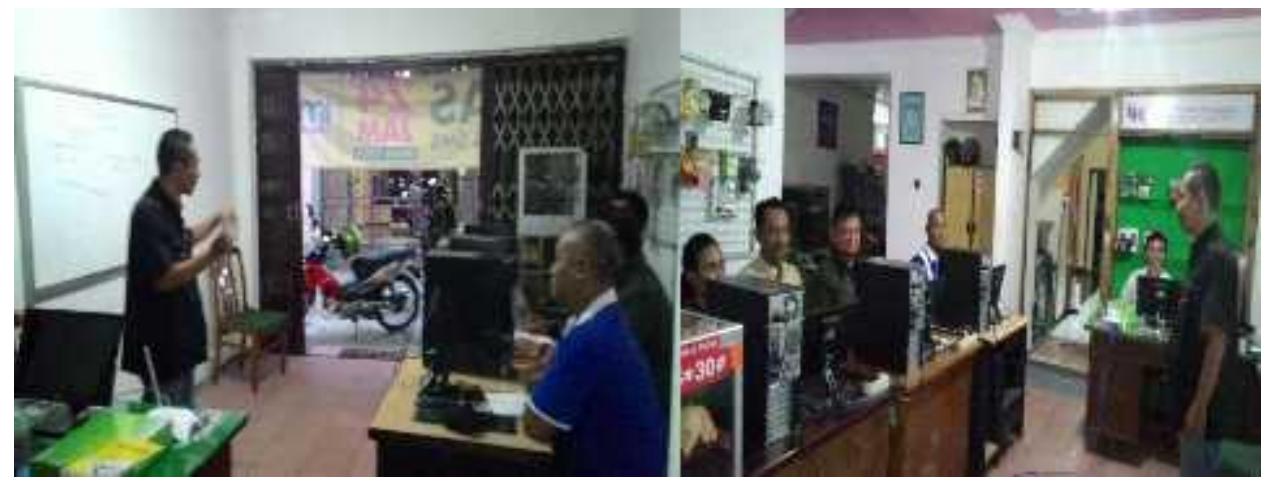

Gambar 2. Kegiatan Pelatihan

Tampilan sistem aplikasi penjualan berbasis Web, mulai tampilan profil, alamat, kontak yang bisa
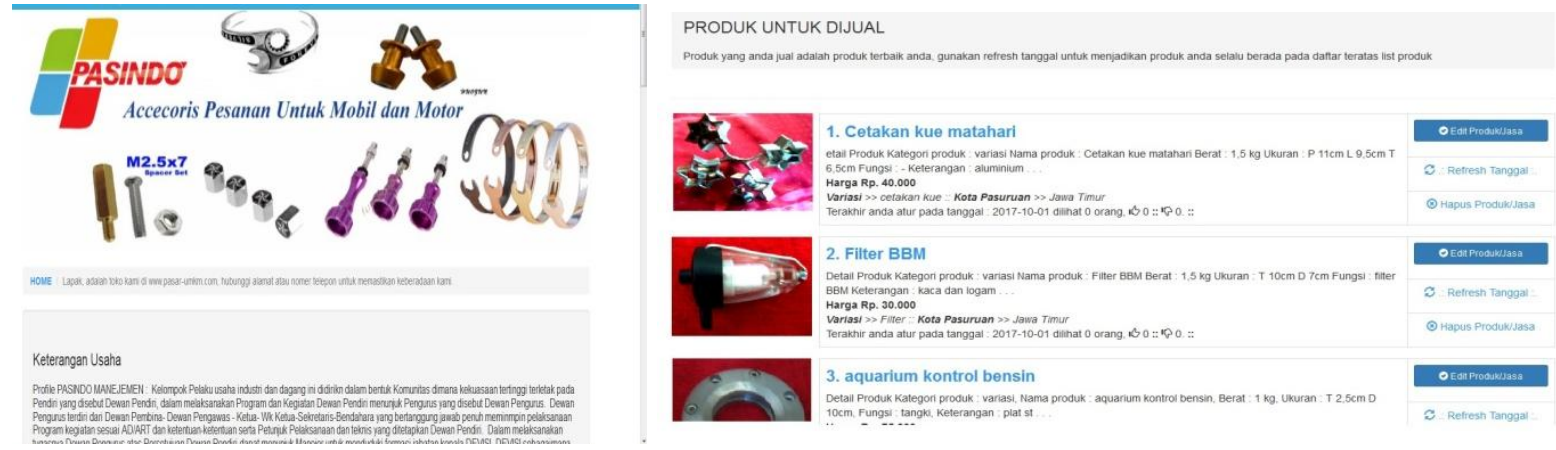

di hubungi Pasindo.

Volume 1, Number 2, November 2017 | 191

Penguatan Pengelolaan Ternak W akaf Hibah Produktif melalui Fermentasi Pakan Ternak sebagai Alternatif Pemberdayaan Santri menuju Pesantren Yatim yang Mandiri

Nihayatu A slamatis Solekah, U1fi Kartika Oktaviana 
This work is licensed under a Creative Commons Attribution-ShareAlike 4.0 International License. CC BY SA

Gambar 3. Hasil Kegiatan Pelatihan E-commerce

Produk yang bisa dijual ada beberapa bisa ditunjukkan oleh Pasindo dengan menekan klik pada detail produk dan akan keluar tampilan tentang gambar salah satu produk dan pihak yang memproduksi serta alamatnya dan berisi tampilan tentang harga produk, jumlah yang dibeli dengan tombol keranjang untuk pembelian dan isian dari pembeli tentang testimoni, komentar serta pertanyaan. menunjukkan tampilan untuk seorang pembeli baru yang akan melakukan pembelian pada salah satu produk yang dipilih dan telah melakukan pembuatan LOGIN dengan username dan password dan dimana seorang pembeli untuk sudah login maka bisa melakukan pembelian. Apabila sudah melakukan pembelian bisa dilihat di tombol belanja.

Kemudian menunjukkan tampilan data untuk seorang pembeli yang melakukan pembelian. Dan apabila sudah melakukan pemesanan yang terlihat pada daftar produk dan tabel pembelian barangnya. Serta menunjukkan tampilan data indentitas seorang pembeli yang melakukan pembelian.

Adapun data penjualan dengan sampel 30 produk yang di stok di Pasindo yaitu :

\section{Tabel 1 Nama Produk yang Dijual}

\begin{tabular}{clcr}
\hline $\begin{array}{c}\text { Kode } \\
\text { barang }\end{array}$ & Nama barang & $\begin{array}{c}\text { Ukuran } \\
/ \mathrm{cm}\end{array}$ & $\begin{array}{r}\text { Berat } \\
/ \mathrm{gr}\end{array}$ \\
\hline AKB001 & Aquarium kontrol bensin & 2.5 & 1000 \\
\hline AKB002 & Aquarium kontrol bensin & 10 & 1000 \\
\hline BSS001 & Batman ster skok & 20 & 1000 \\
\hline
\end{tabular}

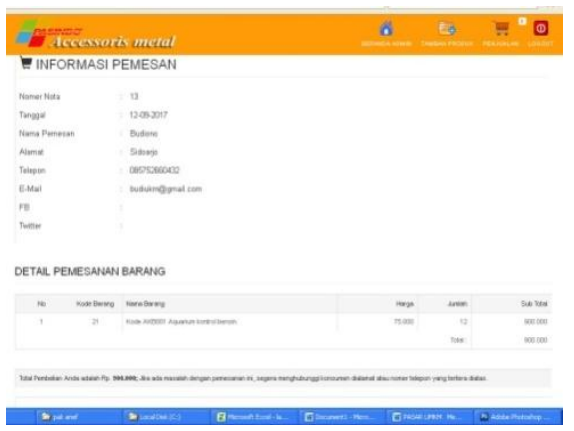


This work is licensed under a Creative Commons Attribution-ShareAlike 4.0 International License. CC BY SA

\begin{tabular}{|c|c|c|c|}
\hline BSS002 & Batman ster skok & 10 & 1000 \\
\hline KPS001 & Kotak peninggi ster & 8.4 & 55100 \\
\hline KPS002 & Kotak peninggi ster & 5.3 & 55100 \\
\hline KPS003 & Kotak peninggi ster & 2.5 & 55100 \\
\hline KPS004 & Kotak peninggi ster & 6.9 & 39200 \\
\hline KPS005 & Kotak peninggi ster & 5.3 & 39200 \\
\hline KPS006 & Kotak peninggi ster & 2.5 & 39200 \\
\hline CKM001 & Cetakan kue matahari & 11 & 1500 \\
\hline CKM002 & Cetakan kue matahari & 9.5 & 1500 \\
\hline CKM003 & Cetakan kue matahari & 6.5 & 1500 \\
\hline FB001 & Filter BBM & 10 & 1500 \\
\hline FB002 & Filter BBM & 7 & 1500 \\
\hline Ma001 & Manipol & 8 & 0,01 \\
\hline Ma002 & Manipol & 6 & 0,01 \\
\hline Ma003 & Manipol & 4 & 0,01 \\
\hline Pu001 & Puly & 14.8 & 2600 \\
\hline Pu002 & Puly & 3.70 & 2600 \\
\hline TP001A & Tutup karburatorA & 7 & 7800 \\
\hline TP002A & Tutup karburatorA & 4.9 & 7800 \\
\hline TP001B & Tutup karburatorB & 6.2 & 106400 \\
\hline ТР002B & Tutup karburatorB & 4.9 & 106400 \\
\hline TP001C & Tutup karburatorC & 7.3 & 6200 \\
\hline
\end{tabular}


ENGAGEMENT

Gurnal Pengabdian Kepada Masyarakat

ISSN : 2579-8375 (Print)

ISSN : 2579-8391 (Online)
This work is licensed under a Creative Commons

Attribution-ShareAlike 4.0 International License. CC BY SA

\begin{tabular}{cccc}
\hline TP002C & Tutup karburatorC & 3.5 & 6200 \\
\hline TK001 & Tutup knalpot & 6.5 & 7800 \\
\hline TK002 & Tutup knalpot & 4.3 & 7800 \\
\hline WP001 & Water pump & 15 & 1050 \\
\hline WP002 & Water pump & 15 & 1050 \\
\hline WP003 & Water pump & 13 & 1050 \\
\hline
\end{tabular}

Dengan menggunakan rumus perbandingan:

$$
\frac{14}{5.120 .000}=\frac{2}{4.356 .00} \quad \square \quad 2.178 .000-365.714=1.812 .286
$$

Jadi perbulan meningkat Rp 1.812.286 
Pada Diagram pendapatan selama kegiatan pendampingan dalam 2 bulan menggunakan e-commerce sebesar 4.356.000, jika dikali 7 kali akan lebih besar pendapatan yang diterima oleh UMKM pengrajin Logam.

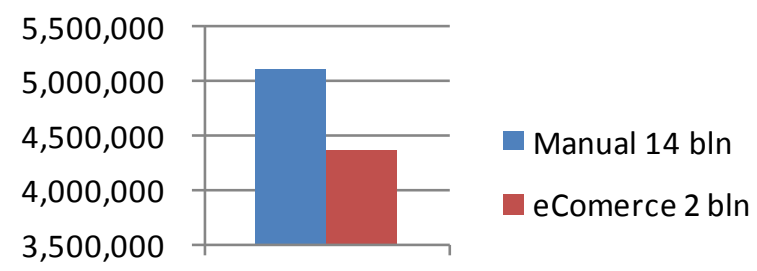

1

Dari data penjulan selama 14 bulan sebelum menggunakan aplikasi penjualan berbasis Web pada sampel 30 produk menghasilkan laba bersih sebesar Rp 5.120.000. Penjualan selama 2 bulan setelah menggunakan aplikasi Web menghasilkan laba bersih sebesar Rp 4.356.000. Dari pernyataan di atas dapat disimpulkan bahwa laba mengalami peningkatan sebesar Rp1.812.286 setiap bulan setelah menggunakan aplikasi penjualan berbasis Web (E-Commerce).

\section{Kesimpulan dan Saran}

Dari paparan di atas, dapat disimpulkan bahwa: Dalam pendampingan e-commerce dengan aplikasi berbasis Web mampu memberikan perubahan dalam penataan menajemen keuangan proses produksi dan administrasi menjadi lebih tertib dan terkontrol dengan baik, dibanding sebelumnya yang masih tercampur antara kebutuhan proses produksi dan keperluan kebutuhan rumah tangga. Selain itu, para pelaku usaha juga dengan mudah mengetahui jumlah stok barang yang tersedia dibanding sebelumnya yang hanya tersedia barang apabila ada pesanan dari pelanggan.

Dengan menggunaan aplikasi penjualan berbasis Web (E-commerce) dapat meningkatkan laba penjualan sebesar Rp1.812.286 setiap bulan dibanding tanpa menggunakan aplikasi penjualan berbasis Web, karena jaringan informasi lebih luas dan distribusi penjualan langsung dari produksi ke konsumen.

Dari kesimpulan di atas, maka penulis memberikan saran sebagai berikut:

Pertama, Pemerintah dan pihak UMKM perlu memanfaatan Teknologi Informasi untuk mengontrol kualitas produk yang akan dijual oleh UMKM, agar laba penjualan meningkat secara signifikan. 
Kedua, masih diperlukan perhatian khusus dalam pengelolaan database stock barang dan pemanfaatan sistem penjualan online, karena SDM UMKM kurang memahami penggunaan teknologi informasi berbasis online.

\section{Daftar Referensi}

Haryanti, Sri, and Tri Irianto. "Rancang Bangun Sistem Informasi E-Commerce Untuk Usaha Fashion Studi Kasus Omah Mode Kudus.” Journal Speed 3, no. 1 (2011): 8-14.

Irmaw ati, Dewi. "Pemanfaatan E-Commerce Dalam Dunia Bisnis." Jurnal Ilmiah Orasi Bisnis 6, no. 2 (2011): 95-112.

Karmawan, I Gusti Made. "DAMPAK PENINGKATAN KEPUASAN PELANGGAN DALAM PROSES BISNIS E-COMMERCE PADA PERUSAHAAN AMAZON. COM.” ComTech 5, no. 2 (2014): 748-762.

Khristianto, Wheny. "Penggunaan Teknologi Informasi Di Usaha Kecil Menengah (Studi Pada Usaha Kecil Menengah Di Wilayah Gedong Meneng).” Universitas Islam Lamongan, 2012.

Mawardi, Sandy, Eri Satria, and Dewi Trisnawati. "Perancangan Web Kelas Online Dengan Metodelogi WISDM Berbasis Learning Manajement System Di MAN PAMEUNG PEUK." Jurnal Algoritma 9, no. 37 (2012): 1-7.

Nugrahani, Dewi Shanti. “E-Commerce Untuk Pemasaran Produk Usaha Kecil Dan Menengah.” Segmen: Jurnal Manajemen dan Bisnis 7, no. 1 (2011): 1-16.

Nuryanti. "Peran E-Commerce Untuk Meningkatkan Daya Saing Usaha Kecil Dan Menengah UKM)." Jurnal Ekonomi 21, no. 4 (2013): 1-15.

Pramudiya, Handaru Eri, Yonathan Dri Handarkho, and Flourensia Sapty Rahayu. "Pengimplementasian CRM Pada Pembangunan E-Commerce Untuk Usaha Mikro Kecil Menengah ( Studi Kasus : Dolanan Puzzle )." Buana Informatika 6, no. 4 (2015): 257-268.

Purbo., Onno W. Buku Pintar Internet Membangun Web E-Commerce. Yogyakarta: Diglib AMIKOM, 1996.

Setiawan, M Ikhsan, and agus sukoco. "2015 PENGEMBANGAN PUSAT BISNIS (CENTRAL BUSINESS DISTRICT) DENGAN POLA KERJASAMA PEMERINTAH-SWASTA (KASUS WILAYAH KAKI SURAMADU SISI SURABAYA)." doi.org (2017). Accessed October 21, 2017. https://osf.io/preprints/inarxiv/kbwme/.

Sidharta, Iwan, and Rahmahwati Sidh. "Pengukuran Persepsi Manfaat Dan Persepsi Kemudahan Terhadap Sikap Serta Dampaknya Atas Penggunaan Ulang Online Shopphing Pada E-Commerce." Jurnal Computech \& Bisnis 8, no. 2 (2014): 92-100.

Suhud, Ridwan, and M. Yudhi Rezaldi. "E-Commerce System Development of Society of Small and Medium Enterprises Karya Mandiri in Tegal." Widyariset 17, no. 1 (2014): 49-58.

Wajdi, Muh. Barid Nizaruddin, Yuli Choirul Ummah, and Devit Etika Sari. "UKM Development Business Loan.” IJEBD (International Journal Of Entrepreneurship And Business Development) 1, no. 1 
This work is licensed under a Creative Commons Attribution-ShareAlike 4.0 International License.

(October 1, 2017): 99-109. Accessed November 9, 2017.

http://jurnal.narotama.ac.id/index.php/ijebd/article/view/350.

Wajdi, Muh Barid Nizarudin. "Paradigma Pergeseran Educational Technology Menuju Instructional Technology” (2017).

“Industri Pasuruan.” Http:/ / pasuruankota.go.id. 